\title{
QUÉ ES LA EPIGENÉTICA
}

\section{WHAT IS EPIGENETICS?}

Sabrina Rivero Canalejo ${ }^{1}$

\section{Resumen}

El término epigenética hace referencia al estudio de los mecanismos por medio de los cuales el genotipo, o la información genética de una célula u organismo, da origen al fenotipo, el conjunto de características observables de una célula u organismo. Hoy sabemos que los mecanismos epigenéticos actúan generando huellas sobre el ADN que van a determinar la forma en la que se expresan nuestros genes. Estos mecanismos son esenciales para el establecimiento y el mantenimiento del patrón específico de expresión génica de cada tipo celular concreto. Así, como guardianes de la identidad celular, estos mecanismos actúan en respuesta a un complejo proceso de regulación. No obstante, al igual que ocurre en el caso del genoma, el epigenoma, o información epigenética de una célula u organismo, es también vulnerable a la influencia de factores externos que podrían generar huellas epigenéticas accidentales asociadas en muchos casos a la aparición de patologías. Ahora sabemos que, en cada nueva generación, las huellas epigenéticas son borradas y reiniciadas de nuevo, lo que deja pocas posibilidades de heredar marcas epigenéticas, ya sean programadas, accidentales o inducidas por el medioambiente. No obstante, estudios recientes en animales han demostrado que existe una aparente resistencia al borrado completo de las huellas epigenéticas, lo que permitiría una verdadera herencia epigenética transgeneracional. Aunque en los últimos

\footnotetext{
${ }^{1}$ Profesora del Departamento de Citología e Histología Normal y Patológica, Facultad de Medicina, Universidad de Sevilla, e Investigadora Postdoctoral del Departamento de Biología del Genoma del Centro Andaluz de Biología Molecular y Medicina Regenerativa (CABIMER) en Sevilla. srivero@us.es.

En buena medida este trabajo es síntesis de muchas enseñanzas. Por ese motivo debo hacer explícito el agradecimiento a José Carlos Reyes del Centro Andaluz de Biología Molecular y Medicina Regenerativa en Sevilla, en cuyo laboratorio de epigenética y expresión génica aprendí mucho durante muchos años. Gracias también a Pablo Huertas, y a todos los miembros de su laboratorio del Centro Andaluz de Biología Molecular y Medicina Regenerativa en Sevilla, con quien he podido seguir trabajando como investigadora en esta misma línea. A Macario Alemany, filósofo del derecho de la Universidad de Alicante, le debo agradecer una primera lectura crítica de este trabajo especialmente valiosa para mi, al permitirme dialogar con alguien atento desde hace tiempo a los principales debates en el mundo de la bioética. Finalmente, gracias a Ángel Barco, del Instituto de Neurociencias de Alicante por su revisión final a este texto, sin la cual, sin duda, sería mucho peor.
} 
años se han producido grandes avances en esta área, son numerosas las cuestiones que permanecen por responder. Este trabajo pretende clarificar determinados conceptos esenciales que nos ayuden a entender qué es la epigenética, y que sabemos acerca de la herencia de estas huellas que marcan nuestro ADN.

\section{Abstract}

The term epigenetics refers to the study of the mechanisms by which the genotype, or the genetic information of a cell or organism, gives rise to the phenotype, the observable characteristics of a cell or organism.

Today we know that epigenetic mechanisms act by generating marks on DNA that determine the way in which our genes are expressed. These mechanisms are essential for the establishment and maintenance of the specific gene expression pattern of each specific cell type. Thus, as guardians of cellular identity, these mechanisms act in response to a complex process of regulation. However, as in the case of the genome, the epigenome, or epigenetic information of a cell or organism, is also vulnerable to the influence of external factors that could generate accidental epigenetic marks associated in many cases with the appearance of pathologies. Now we know that, in each new generation, epigenetic marks are erased and restarted again, which leaves little chance of inheriting epigenetic marks, whether programmed, accidental or environmentally induced. However, recent studies in animals have shown that there is an apparent resistance to the complete erasing of epigenetic marks, which would allow a true transgenerational epigenetic inheritance.

Although in recent years there have been great advances in this area, there are many questions that remain to be answered. This work aims to clarify certain essential concepts about what epigenetic sis, and what we know about the inheritance of these marks that mark our DNA.

\section{Palabras Clave}

Epigenética, epigenoma, herencia epigenética transgeneracional.

\section{Keywords}

Epigenetics, epigenome, transgenerational epigenetic inheritance. 


\section{INTRODUCCIÓN}

En los años 50 el embriólogo inglés ConradWaddington introdujo el término epigenética para hacer referencia al estudio de los mecanismos precisos por medio de los cuales el genotipo -la información genética de una célula u organismo- da origen al fenotipo -el conjunto de características observables de una célula u organismo-. Waddington intentó comprender el fenómeno crucial del desarrollo sin reducirlo a la genética (aunque considerando la genética como el fundamento o punto de partida para su estudio), motivo por el cual se le considera como el padre de la epigenética. Para ello, Waddington propuso la metáfora del "paisaje epigenético", una metáfora grafica que pretendía explicar el desarrollo de los organismos mediante la imagen de un paisaje compuesto por una superficie ondulante con cimas y valles, que representan las vías por las cuales se desplazan las células del organismo en su proceso de diferenciación ${ }^{2}$. El paisaje representaría todo aquello que influye y regula la actividad de los genes durante este proceso.

Durante el proceso de desarrollo de un embrión la célula original fecundada va a dar lugar, de forma secuencial, a una multitud de tipos celulares distintos que difieren en su función y en su fenotipo, pero que contienen, sin embargo, la misma información genética o genotipo. ¿Qué hace entonces que dos células que tienen la misma información genética sean diferentes pudiendo tener distintas funciones? La respuesta está en el patrón específico de expresión génica, es decir, en la forma en la que los genes son expresados; mientras que unos genes están activos en unos tipos celulares, otros están inactivos, estableciéndose así un patrón de expresión característico para cada tipo celular concreto y en cada momento. Ahora sabemos que este patrón de expresión característico es adquirido durante el proceso de diferenciación gracias, en parte, a mecanismos epigenéticos que van a generar huellas sobre el $\mathrm{ADN}$, huellas que van a determinar, en última instancia, la forma en la que los genes se expresan. Así, por ejemplo, los genes relacionados con la formación de los recuerdos estarán activos o "encendidos" en una neurona, pero inactivos o "apagados" en una célula hepática, dónde no van a cumplir ninguna función.

\footnotetext{
${ }^{2}$ C.H. Waddington (1957) The Strategy of the genes. George Allen and Unwin, London.
} 
Ahora sabemos también que los mecanismos epigenéticos son una de las principales herramientas que poseen las células y los organismos para modular la actividad de sus genes, y que las modificaciones epigenéticas contribuyen a establecer y mantener el patrón distintivo de expresión génica de cada tipo celular concreto en los organismos multicelulares como nosotros, dotando a las células de una identidad. Estas modificaciones son llevadas a cabo por una multitud de factores epigenéticos distintos y se producen como resultado de un complejo proceso de regulación.

En los últimos años, la epigenética ha despertado un enorme interés no sólo entre científicos de distintas áreas, sino también en la sociedad en general, sobre todo por las posibles implicaciones que en nuestra salud y en la de las futuras generaciones pueden tener estas huellas adquiridas durante nuestra experiencia de vida. Es por ello que se hace cada vez más necesario clarificar determinados conceptos esenciales que nos ayuden a entender qué es la epigenética, y qué sabemos acerca de la herencia de estas huellas que marcan nuestro ADN.

\section{HUELLAS EPIGENÉTICAS PROGRAMADAS}

En la actualidad tenemos conocimiento de que la regulación de la expresión génica está mediada por mecanismos epigenéticos que incluyen distintas modificaciones químicas y físicas que afectan al ADN sin producir cambios en su secuencia y que van a generar huellas "epi-genéticas", es decir, sobre el ADN, las cuales van a determinar, en última instancia, la forma en la que los genes son expresados ${ }^{3}$.Cada vez sabemos más acerca de los mecanismos moleculares por los cuales estas huellas son generadas. Una multitud de factores epigenéticos diferentes generan una multitud de huellas epigenéticas distintas. En muchos casos es la combinación de un conjunto determinado de huellas la que va a determinar que un gen se encienda o se apague. Así, a través de la regulación de la

\footnotetext{
${ }^{3}$ Modificaciones químicas como la adición de grupos metilo que tiene lugar directamente sobre la molécula de ADN y que se asocia con la represión de la expresión génica, o modificaciones físicas que determinan la accesibilidad del ADN, forman parte de estos mecanismos epigenéticos que gobiernan la expresión génica. Revisado en T.Kouzarides (2007) Chromatin modifications and their function. Cell 128:693-705.
} 
expresión génica los mecanismos epigenéticos contribuyen a generar la enorme variedad de células y tejidos presentes en los organismos multicelulares.

Es lógico pensar por tanto que, por su papel crucial en el desarrollo y en el mantenimiento de la identidad celular, los mecanismos epigenéticos deben actuar en respuesta a un programa altamente regulado. Cada tipo celular concreto presentará así un patrón de huellas característico que va a conferir a las células una identidad determinando qué genes estarán activos y cuales inactivos. Esta identidad debe permanecer a lo largo de la vida de una célula u organismo y debe ser transmitida a la descendencia, es decir, a las células que de ella surjan tras las sucesivas divisiones celulares. ¿En respuesta a qué se generan estas huellas epigenéticas? Waddington utilizó el término "paisaje" para hacer referencia al conjunto de factores que durante el desarrollo desencadenan estas modificaciones epigenéticas ${ }^{4}$. Para Waddington el paisaje es un espacio multidimensional enclavado en el metabolismo celular, y son las redes formadas por las interacciones entre los distintos genes y sus productos las que realmente configuran el paisaje. Estas interacciones, acompañadas o no de modificaciones ambientales (que actúan sobre la superficie del paisaje), pueden producir una alteración significativa de este paisaje que cambie el destino de una célula. Son por tanto factores intracelulares los que determinan en primer lugar la generación de las huellas o marcas epigenéticas, pero, y esto cobra especial relevancia, también, los cambios ambientales serían una variable con capacidad de introducir cambios en ese paisaje.

De ahí que en la comunidad científica se defina la epigenética como el conjunto de modificaciones que sobre el $\mathrm{ADN}$ se producen en respuesta a estímulos tanto intracelulares como extracelulares. Los estímulos intracelulares serían aquellos derivados del interior de la célula, que es donde reside la información para la generación

\footnotetext{
${ }^{4}$ Curiosamente, Ortega y Gasset, influenciado por el biólogo alemán von Uexküll, usó el término paisaje en referencia, en su caso, a la importancia que sobre la vida tiene el entorno que nos rodea: "para entender una vida, humana o animal, habrá que hacer antes el inventario de los objetos que integran su medio propio o, como yo prefiero decir, su paisaje". Como el mismo Ortega explicaría, el paisaje o las circunstancias son "las cosas mudas" que nos rodean, que se hallan cerca, muy cerca. El concepto de paisaje ya había sido utilizado anteriormente por von Uexküll, un biólogo alemán que a principios del siglo XX señaló la necesidad de considerar el medio ambiente de un individuo para poder comprenderlo. J. Ortega y Gasset. Obras completas, 2ª edición. Revista de Occidente, Madrid, 1950, p. 299.
} 
de las huellas epigenéticas programadas. Los extracelulares harían referencia al conjunto de factores externos -tales como la nutrición o ciertos contaminantes atmosféricos- cuyo efecto ha sido relacionado con la adquisición de distintas huellas epigenéticas, huellas en este caso accidentales inducidas por el medioambiente.

\section{INFLUENCIA DEL AMBIENTE EN NUESTROS GENES}

Al igual que ocurre en el caso del genoma, el epigenoma-la información epigenética global de una célula $\mathrm{u}$ organismo- es también vulnerable a factores externos o ambientales que van generar huellas que se asocian en muchos casos a la aparición de patologías, siendo especialmente susceptible durante los primeros años de vida, y muy especialmente durante la embriogénesis, que es la etapa en la que se establecen los patrones de huellas epigenéticas que van a determinar la identidad de las células.

Un ejemplo de ello lo encontramos en los estudios derivados de lo que se ha conocido como invierno del hambre holandés o Hongerwinter. A finales de la Segunda Guerra Mundial, parte de la población holandesa se vio sometida a una hambruna extrema que provocó una fuerte desnutrición. Las consecuencias derivadas de esta situación pudieron ser estudiadas en la población superviviente y en su descendencia. Los niños nacidos de mujeres que estaban embarazadas durante la hambruna desarrollaron en su vida adulta con mayor frecuencia, en relación con sus hermanos concebidos antes o después de la hambruna, problemas como diabetes, hipertensión arterial, obesidad o enfermedad cardiovascular, problemas también presentes, aunque en menor grado, en los hijos que luego ellos mismos tuvieron. Casi seis décadas después de la hambruna, diferentes estudios han demostrado la existencia de cambios en las marcas epigenéticas de varios genes en estos individuos, entre ellos genes relacionados con el crecimiento, con el metabolismo del colesterol, o con la esquizofrenia ${ }^{5}$.

Este caso ha sido tradicionalmente usado como un ejemplo de herencia epigenética, sin embargo, a falta de nuevos datos, no se puede descartar que los efectos observados en la descendencia de estas mujeres embarazadas durante la hambruna y en los nietos de éstas

\footnotetext{
${ }^{5}$ B.T. Heijmanset al. (2008) Persistent epigenetic differences associated with prenatal exposure to famine in humans. PNAS 105:17046-17049.
} 
hayan sido consecuencia de las condiciones -en este caso la hambruna- a la que también fueron expuestos los fetos y los gametos en desarrollo de éstos (óvulos y espermatozoide) en el útero de estas mujeres. Esto explicaría los problemas desarrollados posteriormente por ellos y sus hijos. Es muy importante no confundir este fenómeno, conocido como exposición intrauterina, con la verdadera herencia epigenética transgeneracional ${ }^{6}$ en la que las huellas son transmitidas de padres a hijos a lo largo de las generaciones aun cuando éstos últimos no han estado expuestos a las condiciones que han generado estas modificaciones epigenéticas. Lo que si puso en evidencia este estudio fue el efecto que la desnutrición tuvo en la regulación de ciertos genes en los que se encontraron huellas epigenéticas no presentes en individuos que no habían padecido esta situación, constituyendo un ejemplo de la vulnerabilidad de nuestro epigenoma frente a determinados agentes externos, que se hace especialmente patente durante nuestra experiencia de vida intrauterina. Si este caso constituye o no un ejemplo de verdadera herencia epigenética transgeneracional permanece aún por dilucidar.

En los últimos años, numerosos estudios, que podemos enmarcar en el área de lo que hoy se conoce cómo epigenética ambiental ${ }^{7}$, se han dedicado al análisis del posible impacto que determinados factores externos -cómo la nutrición, el cuidado materno durante los primeros años de vida o distintos contaminantes atmosféricos- pueden tener en el epigenoma. Así, se han encontrado, por ejemplo, cambios epigenéticos en muchos trastornos neurológicos que pueden correlacionarse con la exposición a ciertos factores ambientales en estudios en animales de laboratorio. Sin embargo, es especialmente

\footnotetext{
${ }^{6}$ Para que se produzca una verdadera herencia epigenética transgeneracional, las marcas epigenéticas y los fenotipos deben transferirse a las siguientes generaciones, de manera que, en una hembra gestante, los cambios fenotípicos tendrían que mantenerse durante al menos 4 generaciones. Cambios mantenidos durante 3 generaciones podrían ser el resultado de la exposición intrauterina del embrión y de la línea germinal de éste, ya en desarrollo, al mismo factor ambiental al que está expuesta directamente la madre. En las investigaciones de exposiciones que operan antes de la gestación a través de la línea germinal materna o paterna, el fenotipo de la descendencia de tercera generación es suficiente para establecer la herencia epigenética transgeneracional. Revisado en S. D. van Otterdijk and K. B. Michels (2016) Transgenerational epigenetic inheritance in mammals: ihow good is the evidence? FASEB Journal 30:2457-2465.
}

${ }^{7}$ V. Bollati and A. Baccarelli (2010) Environmental epigenetics. Heredity 105:105-122. 
importante destacar que no está claro si estas alteraciones epigenéticas son parte de la causa del problema o son una mera consecuencia indirecta de la patología ${ }^{8}$.

En definitiva, es indudable que el ambiente puede influir en la expresión de nuestros genes, influencia que se refleja, en muchas ocasiones, en forma de huellas epigenéticas que pueden permanecer a lo largo de la vida de un individuo pudiendo conducir a la aparición de enfermedades. Sin embargo, las posibles consecuencias transgeneracionales que estas huellas adquiridas pudieran tener son un asunto aparte.

\section{¿QUÉ SABEMOS DE LA HERENCIA EPIGENÉTICA DE PADRES A HIJOS?}

¿Qué sucede cuando un organismo se reproduce? ¿Transmite las marcas o improntas en el genoma a otro organismo? ¿Puede la información del ambiente transmitirse de generación en generación? La heredabilidad de las huellas epigenéticas que un organismo adquiere a lo largo de su experiencia de vida es a día de hoy uno de los temas más controvertidos de la biología.

Como guardianes de la identidad celular, los mecanismos epigenéticos deben ser persistentes y deben ser transmitidos a través de las sucesivas divisiones celulares, de manera que una célula pueda asegurar su identidad en un lugar, así como la de las células que de ella se originen. De hecho, sólo las células embrionarias tienen genomas lo suficientemente flexibles como para adquirir muchos tipos diferentes de identidades y generar así todos los tipos de células en el organismo. Una vez que las células del embrión han adquirido identidades fijas -se han convertido en células intestinales, células sanguíneas o células nerviosas, por ejemplo-, no suele haber vuelta atrás. Sin embargo, hasta el momento, poco se sabe acerca de los mecanismos moleculares por los cuales las marcas epigenéticas son transmitidas de una célula madre a su célula hija durante el proceso de división celular, con una excepción: la metilación del ADN, una modificación epigenética que consiste en la adición de una pequeña "etiqueta" (un grupo metilo) directamente sobre la molécula de $\mathrm{ADN}$ y que se asocia generalmente con

\footnotetext{
${ }^{8}$ B. del Blanco and A. Barco (2018) Impact of environmental conditions and chemicals on the neuronal epigenome. Current Opinion in Chemical Biology 45:157-165.
} 
la represión de genes ${ }^{9}$.Durante el proceso de división celular, al igual que ocurre con la información genética contenida en el $\mathrm{ADN}$, el estado de metilación de la célula madre es copiado y transmitido a la célula hija, manteniéndose así la memoria del estado metilado en la molécula de ADN hija. De ahí que la metilación del ADN se haya considerado como un mecanismo epigenético capaz de mantener las identidades celulares durante toda la vida.

Sin embargo, aunque el patrón de metilación del ADN se conserva fielmente en las células diferenciadas, es eliminado completamente en las células germinales primordiales, es decir, en las células que darán lugar a óvulos y espermatozoides, así como poco después de la concepción, en el desarrollo temprano del embrión ${ }^{10}$. Así, ahora sabemos que en cada nueva generación las marcas epigenéticas son borradas en los gametos y "reiniciadas" tras la fertilización ${ }^{11}$. Estas dos rondas de borrado dejan pocas posibilidades de heredar marcas epigenéticas, ya sean programadas, accidentales o inducidas por el medioambiente ${ }^{12}$.La evolución parece haber ideado un mecanismo para garantizar de esta manera la eliminación de marcas potencialmente nocivas que la experiencia de vida de un progenitor pueda haber impuesto.

No obstante, estudios recientes en animales han demostrado una aparente resistencia al borrado completo de las marcas epigenéticas, lo que permitiría una verdadera herencia epigenética transgeneracional. Se han descrito ya varios casos de genes cuyas marcas escapan a este borrado permaneciendo en los gametos, óvulos y espermatozoides, siendo transferidas a la descendencia. Un estudio de 2014 demostró en roedores la heredabilidad del estado de metilación del gen que codifica el receptor olfatorio Olfr151, y que provoca el rechazo de los hijos a un olor que los padres asociaban al

\footnotetext{
${ }^{9}$ La metilación consiste en la adición de grupos metilo directamente sobre la secuencia de ADN, y está generalmente asociada con la represión de genes. La metilación puede ocurrir también de una forma no directa, sobre las histonas, que son las proteínas sobre las cuales el ADN se ensambla en el interior del núcleo de la célula. Las histonas constituyen los andamios sobre los cuales la doble hélice de ADN se enrolla formando la cromatina.B.Albertset al. (2015) Molecular Biology of theCell. SixthEdition. Garland Science187-188.

${ }^{10}$ W. Reiket al. (2001) Epigenetic reprogramming in mammalian development. Science 293:1089-1093.

${ }^{11}$ S. Seisenbergeret al. (2012) The dynamics of genome-wide DNA methylation reprogramming in mouse primordial germ cells. Mol. Cell 48:849-862.

12 E. Heard and R. A. Martienssen (2014) Transgenerational Epigenetic Inheritance: Myths and Mechanisms. Cell 157:95-109.
} 
miedo ${ }^{13}$.Otro estudio, también en roedores, ha demostrado que la exposición a lavinclozolina, un fungicida que actúa como disruptor hormonal, durante la determinación del sexo gonadal embrionario afecta a la producción de espermatozoides no solo en los animales tratados (al alcanzar la pubertad), sino también en al menos cuatro generaciones posteriores. Estos problemas de fertilidad se asocian con cambios epigenéticos en los espermatozoides de los animales expuestos y de su descendencia masculina ${ }^{14}$.

Estos datos podrían indicar que, aunque la eliminación de la metilación del ADN durante la diferenciación de las células germinales y la fertilización posterior es bastante extensa, ésta no es completa. Es posible, por tanto, que determinadas secuencias genómicas escapen al borrado, pudiendo haber evolucionado para desempeñar un papel en la transmisión de marcas epigenéticas entre generaciones, es decir, en la transmisión de marcas epigenéticas de padres a hijos ${ }^{15}$. Si la herencia epigenética transgeneracional existe o no en seres humanos, sin embargo, permanece aún por dilucidar.

\section{DISCUSIÓN Y CONCLUSIONES}

En los últimos años la epigenética ha adquirido un gran protagonismo por las posibles implicaciones que la transmisión de los "caracteres adquiridos" durante nuestra experiencia de vida puede tener para la salud de las futuras generaciones. Esto, junto a la provocadora idea de que la herencia epigenética puede desempeñar un papel en la "evolución rápida" de rasgos en respuesta a nuevas experiencias y entornos, ha puesto a la epigenética en el punto de mira de científicos de todas las áreas. Sin embargo, teniendo en cuenta los datos de los que disponemos, se puede decir que, si bien es cierto que "la información ambiental puede quedar grabada en el genoma, la mayoría de estas

\footnotetext{
13 B. G. Dias and K. J. Ressler (2014) Parental olfactory experience influences behavior and neural structure in subsequent generations. Nat. Neuroscience 17:89-96.

14 C. Guerrero-Bosagnaet al.(2010) Epigenetic transgenerational actions of vinclozolin on promoter regions of the sperm epigenome. PLOS ONE5:e13100.

${ }^{15}$ M. Pembreyet al. (2014) Human transgenerational responses to early-life experience: potential impact on development, health and biomedical research. Journal of Medical Genetics 51:563-572.
} 
huellas quedan registradas como "memoria genética" en las células y los genomas de organismos concretos, y no se propagan a lo largo de las generaciones"16.

Distintos estudios en ratones han identificado procesos que pueden considerarse herencia epigenética transgeneracional. Sin embargo, sigue habiendo mucha incertidumbre acerca de si estos procesos son el resultado de una verdadera herencia epigenética transgeneracional o si están influenciados por otros factores, como la genética o la exposición intrauterina a distintos agentes a la que estamos expuestos durante el proceso de gestación. Como se ha insistido anteriormente, es muy importante no confundir este fenómeno con la verdadera herencia epigenética transgeneracional en la que las huellas son transmitidas de padres a hijos a lo largo de las generaciones aun cuando éstos últimos no han estado expuestos a las condiciones que han generado estas modificaciones epigenéticas.

Debe subrayarse igualmente, que en humanos el estudio de la herencia epigenética transgeneracional es más complejo que en animales por varias razones. En primer lugar, porque se requieren estudios longitudinales multigeneracionales con muestras biológicas disponibles durante al menos 3 generaciones (4 si la transmisión es durante la gestación). Hasta la fecha no se han realizado tales estudios. En segundo lugar, los estudios en humanos se caracterizan por la variación individual, las diferencias estocásticas y, especialmente, por las restricciones éticas, que no se aplican en estudios animales, con lo cual difieren profundamente del entorno controlado de los estudios en animales. Por último, la heterocigosidad ${ }^{17}$ de la población humana, derivada del hecho de poseer dos copias diferentes de cada gen, una heredada de nuestra madre y otra de nuestro padre, hace que sea difícil distinguir entre genética y epigenética. Sólo cuando los individuos son genéticamente idénticos y exhiben un rango de variación de fenotipos que son hereditarios, estos pueden atribuirse a la variación epigenética. Todos

\footnotetext{
${ }^{16}$ S. Mukherjee (2017) El gen. Una historia personal. Traducción de Joaquín Chamorro Mielke. DEBATE 478.

${ }^{17}$ Todas nuestras células, con excepción de óvulos y espermatozoides, poseen dos copias de cada gen, una heredada de nuestra madre y otra heredada de nuestro padre. Se dice que un organismo es homocigoto para un gen cuando las dos copias contienen la misma información genética, por ejemplo, para el mismo color de ojos. Un organismo o individuo es heterocigoto para un gen cuando tiene dos versiones distintas de ese gen.
} 
estos factores hacen que sea difícil estudiar la herencia epigenética transgeneracional en humanos.

Comprender completamente la herencia epigenética transgeneracional requerirá de nuevos estudios que permitan hacer una distinción clara entre este proceso y el efecto de las exposiciones intrauterinas y de la evolución cultural. Será fundamental entender cómo se establecen las marcas epigenéticas durante el desarrollo de la vida temprana e identificar las marcas epigenéticas que se mantienen en las generaciones posteriores. Arrojar luz sobre estos procesos puede ayudar a entender si las marcas epigenéticas de los padres influyen en la salud de los hijos y, en su caso, el grado de susceptibilidad de éstos a distintas enfermedades. A este respecto, creo que cabe afirmar que sólo cuando se constate algún tipo de transmisión o heredabilidad de estas marcas, la cuestión de la epigenética va a adquirir propiamente una dimensión ética específica.

Por el momento, por tanto, y frente a cualquier tentación de hacer una comprensión mesiánica de los avances de la ciencia en este ámbito, creo que conviene tener en cuenta la advertencia que nos hace Sidharta Mukherjee en su no por popular menos extraordinario ensayo:"El Gen. Una Historia Personal”. Como señala el autor indio, "es necesaria cierta precaución, puesto que la epigenética también está a punto de transformarse en una idea peligrosa. Las modificaciones epigenéticas son potencialmente capaces de superponer información histórica y ambiental en las células $\mathrm{y}$ en los genomas, pero esta capacidad es especulativa, limitada, idiosincrásica e impredecible. La mayoría de los "recuerdos" epigenéticos son consecuencia de antiguos caminos evolutivos, y no pueden confundirse con nuestro anhelo de dejar legados deseables en nuestros hijos"18.

\section{BIBLIOGRAFÍA}

- B. Albertset al. (2015) Molecular Biology of theCell. SixthEdition. Garland Science 187-188.

\footnotetext{
${ }^{18}$ S.Mukherjee (2017) El gen. Una historia personal. Traducción de Joaquín Chamorro Mielke. DEBATEp. 477.
} 
- B. del Blanco and A. Barco (2018) Impact of environmental conditions and chemicals on the neuronal epigenome. Current Opinion in Chemical Biology 45:157-165.

- B. G. Dias and K. J. Ressler (2014) Parental olfactory experience influences behavior and neural structure in subsequent generations. Nat. Neuroscience 17:89-96.

- B. T. Heijmanset al. (2008) Persistent epigenetic differences associated with prenatal exposure to famine in humans. PNAS 105:17046-17049.

- C. Guerrero-Bosagnaet al.(2010) Epigenetic transgenerational actions of vinclozolin on promoter regions of the sperm epigenome. PLOS ONE5: e13100.

- C.H. Waddington (1957) The Strategy of the genes. George Allen and Unwin, London.

- E. Heard and R. A. Martienssen (2014) Transgenerational Epigenetic Inheritance: Myths and Mechanisms. Cell 157:95-109.

- J. Ortega y Gasset. Obras completas, 2ª edición. Revista de Occidente, Madrid, 1950, p. 299.

- M. Pembreyet al. (2014) Human transgenerational responses to early-life experience: potential impact on development, health and biomedical research. Journal of Medical Genetics 51:563-572.

- S. D. van Otterdijk and K. B. Michels (2016) Transgenerational epigenetic inheritance in mammals: how good is the evidence? FASEB Journal 30:2457-2465.

- S.Mukherjee (2017) El gen. Una historia personal. Traducción de Joaquín Chamorro Mielke. DEBATE.

- S. Seisenbergeret al. (2012) The dynamics of genome-wide DNA methylation reprogramming in mouse primordial germ cells. Mol. Cell 48:849-862.

- T. Kouzarides (2007) Chromatin modifications and their function. Cell 128:693-705.

- V. Bollati and A. Baccarelli (2010) Environmental epigenetics. Heredity 105:105-122.

- W. Reiket al. (2001) Epigenetic reprogramming in mammalian development. Science 293:1089-1093. 